\title{
Author Correction: Bayesian reassessment of the epigenetic architecture of complex traits
}

Daniel Trejo Banos (D), Daniel L. McCartney, Marion Patxot (1D, Lucas Anchieri, Thomas Battram, Colette Christiansen, Ricardo Costeira, Rosie M. Walker (10, Stewart W. Morris, Archie Campbell @), Qian Zhang, David J. Porteous (1), Allan F. McRae, Naomi R. Wray (D), Peter M. Visscher (D), Chris S. Haley (D), Kathryn L. Evans, Ian J. Deary, Andrew M. Mclntosh (D), Gibran Hemani (D), Jordana T. Bell(D), Riccardo E. Marioni \& Matthew R. Robinson (1)

Correction to: Nature Communications https://doi.org/10.1038/s41467-020-16520-1, published online 8 June 2020.

The original version of this Article contains an error in Fig. 3 in which panel B was inadvertently duplicated from panel A. This has been corrected in both the PDF and HTML versions of the Article.

Published online: 09 October 2020

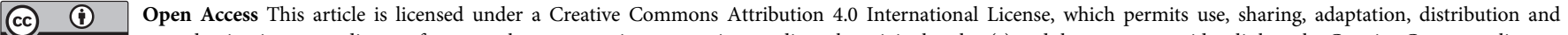
reproduction in any medium or format, as long as you give appropriate credit to the original author(s) and the source, provide a link to the Creative Commons license, and indicate if changes were made. The images or other third party material in this article are included in the article's Creative Commons license, unless indicated otherwise in a credit

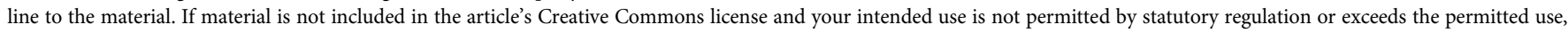
you will need to obtain permission directly from the copyright holder. To view a copy of this license, visit http://creativecommons.org/licenses/by/4.0/.

(c) The Author(s) 2020 